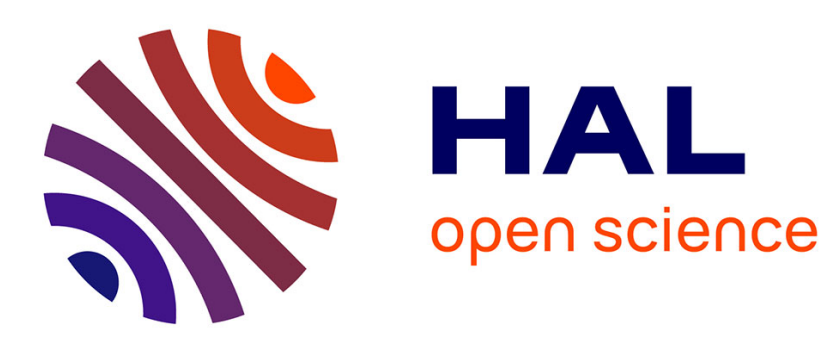

\title{
Crystallinity Increases in Semi Crystalline Polymers During High Rate Testing
}

\author{
G. Swallowe, J. Fernandez, S. Hamdan
}

\section{To cite this version:}

G. Swallowe, J. Fernandez, S. Hamdan. Crystallinity Increases in Semi Crystalline Polymers During High Rate Testing. Journal de Physique IV Proceedings, 1997, 07 (C3), pp.C3-453-C3-458. 10.1051/jp4:1997378 . jpa-00255535

\section{HAL Id: jpa-00255535 https://hal.science/jpa-00255535}

Submitted on 1 Jan 1997

HAL is a multi-disciplinary open access archive for the deposit and dissemination of scientific research documents, whether they are published or not. The documents may come from teaching and research institutions in France or abroad, or from public or private research centers.
L'archive ouverte pluridisciplinaire HAL, est destinée au dépôt et à la diffusion de documents scientifiques de niveau recherche, publiés ou non, émanant des établissements d'enseignement et de recherche français ou étrangers, des laboratoires publics ou privés. 


\title{
Crystallinity Increases in Semi Crystalline Polymers During High Rate Testing
}

\author{
G.M. Swallowe, J.O. Fernandez and S. Hamdan ${ }^{(1)}$ \\ Department of Physics, Loughborough University, Leicestershire, LE11 3TU, U.K.
}

\begin{abstract}
During low rate deformation in tension semi-crystalline polymers can undergo a strain induced crystalisation during deformation which leads to increases in tlow stress. This work extends studies of crystallinity in the polymers PEK, PEEK and PET to compression at high strain rates at a variety of temperatures. All three polymers show large increases in crystallinity when tested at high rates with PEK and PEEK showing increases only at rates of $10^{3} / \mathrm{s}$. It is specuiated that the rapid increases in flow stress reported in polymers at high strain rates may be due to the rapidity of strain induced crystallisation at these strain rates.
\end{abstract}

\begin{abstract}
Résumé: Pendant une déformation à basse vitesse en traction, les polymères semi-cristallins peuvent subir une cristallisation induite par déformation qui conduit à une augmentation de la contrainte d'écoulement. Ce travail concerne l'étude de la cristallinité des polymères PEK, PEEK et PET provoquée par la déformation en compression à vitesses de déformation élevées et à différentes températures. Les trois polymères montrent une forte augmentation de cristallinité lorsqu'ils sont testés à grande vitesse; le PEK et le PEEK ne montrant qu'une augmentation qu'à partir d'une vitesse de $10^{3} / \mathrm{s}$. On suppose que l'augmentation rapide de la contrainte d'écoulement révélée par les polymères à vitesse élevée pourrait être due à la rapidité de la cristallisation induite à ces vitesses de déformation correspondantes.
\end{abstract}

\section{INTRODUCTION}

The rapid increase in flow stress observed in many materials when tested at strain rates in the region of $10^{2}$ and above has been the subject on some controversy. Some workers attribute the increase to instrumental effects arising from friction, inertia etc. [1] and claim that it is not a real material effect whereas others, at least in the case of metals [2], attribute the rapid increase in flow stress to dislocation multiplication and drag and have proposed theoretical models to fit their results. Similar increases in flow stress have been observed in polymers $[3,4]$ at about the same strain rate as those that have been observed in metals and those who argue for instrumental effects would claim that this strengthens their case since it is unlikely that materials whose deformation proceeds by such different mechanisms would experience hardening at the same strain rate. During deformation semi crystalline polymers undergo a hardening mechanism caused by strain induced crystallisation (SIC) in which the alignment of polymer chains during flow gives rise to an increase in overall crystalline content in the material and hence an increase in density and hardness. The SIC is dependant on strain rate and temperature [5] and if it proceeded sufficiently rapidly could provide a mechanism for rapid increase in flow stress. The purpose of the work described here was to investigate the SIC of a selection of high performance semi crystalline polymers in order to evaluate its potential as a source of flow stress increase at high strain rates.

The materials investigated were Polyetheretherketone (PEEK) and Polyetherketone (PEK) with additional work on Polyethylene terephthalate (PET). The structures of all three materials have been extensively characterised $[6,7,8]$. PEEK has a glass transition temperature ( $\mathrm{Tg}$ ) of $145^{\circ} \mathrm{C}$, a melting point of $335^{\circ} \mathrm{C}$ while PEK has a glass transition of $154^{\circ} \mathrm{C}$ and melts at $365^{\circ} \mathrm{C}$. The PET glass transition temperature is $80^{\circ} \mathrm{C}$ and it melts at $230^{\circ} \mathrm{C}$. Studies on PEEK have been carried out by Cebe et al. [9] but they did not carry out mechanical tests at temperatures near or above $\mathrm{Tg}$ and all tests were performed at a low but unspecified strain rate. Major effects on yield stress and toughness as a function of crystallinity were noted with an increase in crystallinity leading to an increase in yield stress and a reduction in toughness. Lee et al [10] carried out an extensive study of yield and crystallinity in annealed samples of PEEK over a range of strain rates from $10^{-3}$ to $0.5 \mathrm{~s}^{-1}$ at both room temperature and at $\mathrm{Tg}$. They found an increase in yield stress with strain rate and crystallinity. They also noted an additional minor melting peak in samples drawn at Tg when examined by Differential Scanning Calorimetry (DSC) whose position was always about 10 degrees above the annealing temperature. Samples drawn at room temperature did not show the additional melting peak but showed a small exothermic peak

(1) Present address: Department of Physics, University Pertanian Malaysia, Sendang 43400, Malaysia 
which was attributed to cold crystallisation. Lee et al [10] attributed the minor melting peak to the melting of crystallites with low degree of order and the main peak to the melting of large stable spherulites. The crystalline percentage of the samples was reduced by drawing in all except the fully amorphous samples. Russo [11] also noted cold crystallisation phenomena in PEEK samples drawn at temperatures below $\mathrm{Tg}$ as evidenced by a cold crystallisation peak observed in samples examined by DSC after drawing. This peak decreased in size with increasing drawing temperature until it was almost absent in samples drawn at $140^{\circ} \mathrm{C}$.

PET has in the past been extensively investigated by many workers. Spruiell et al [5] found a continuous increase in crystallinity with strain rate in the range $10^{-7}$ to $10^{-1} \mathrm{~s}^{-1}$ with very little dependence on the total $\%$ deformation for deformations $>100 \%$. He also reports that crystallinity decreases with test temperature for samples tested above $T_{g}$. More recently Jabarin [12] carried out experiments on amorphous PET above $T_{g}$. He also observed that crystallinity increases with strain rate for samples drawn at the same temperature and that for the samples drawn at the highest rates (rates are not stated explicitly but maximum rate is probably $10^{-1} \mathrm{~s}^{-1}$ ) very little change in crystallisation occurred on annealing.

The general conclusion from the work on PEEK is that during tensile deformation amorphous PEEK is oriented to form aligned regions which then cold crystallise on subsequent heating. This cold crystallisation may occur during the drawing if the temperature of drawing is close to or above Tg. PEEK which is already crystallised during an annealing process before drawing suffers a reduction in crystallinity during drawing due to the destruction of part of the pre-existing crystallites. However some of this crystallinity may be recovered as cold crystallisation during subsequent DSC scans. In the case of PET the conclusions are similar except that drawing at temperatures of $20^{\circ}$ or above increases crystallinity without the need for annealing and the strain rate has a marked influence of the crystalline content even at low rates. Spruiell et al concluded that the higher strain rates allow molecules less time to relax back to the coiled configuration after alignment under stress before other molecules are also stretched and the configurational entropy of the system becomes such that the formation of crystalline material is possible. The work described here extends investigations to higher strain rates for both materiais and to the closely related polymer PEK. It also extends the investigation of SIC to compression tests. almost all previous work having been carried out in tension and, in particular, searches for crystallisation effects at strain rates of $10^{2}$ and greater.

\section{EXPERIMENTAL PROCEDURE AND RESULTS}

Samples were tested in compression at a range of temperatures using a Hounsfield H50KM Universal tist machine (low strain rates), a Dartec hydraulic test machine to achieve intermediate strain rates $(\sim 1)$ and a range of drop weight and cross-bow based high strain rate test equipment $[13,14]$ at the higher strain rates $\left(10^{2}-10^{2}\right)$. PEEK and PEK samples were machined from ICI supplied plaque grade $150 \mathrm{G}$ (PEEK) and grade 220G (PEK) and were small right cylinders of diameter $7 \mathrm{~mm}$ and height $3.5 \mathrm{~mm}$ (the plaque thickness). PET samples wert prepared from $2.4 \mathrm{~mm}$ thick granules of ICI grade B73 and were machined into $4.3 \mathrm{~mm}$ diameter cylinders. In every case samples were heated for 30 minutes in air on a hot plate at the test temperature immediately prior to carrying out the tests. Samples were then tested in preheated test equipment. Data was recorded to total compressive strains of -0.4 or greater. The tinal sample strain depended somewhat on the temperature of the test and was as high as 1.1 in some cases. After testing samples were examined by means of Differential Scanning Calorimetry (DSC) and X-ray diffraction.

\subsection{Mechanical testing}

Figure 1 illustrates data taken from tests on PEK and PEEK at $20^{\circ} \mathrm{C}$. The rapid increase in flow stress at the higher strain rates is clearly visible as is the reduction in flow stress with strain due to adiabatic heating in tests carried out at intermediate strain rates. A summary of the flow stress at a strain of 0.1 together with crystallinity data for the PET samples is given in Table 1 and flow stress data for PEEK/PEK is included in Table 2. The PET data shows a peak in the flow stress at the high strain rate tests carried out at $50{ }^{\circ} \mathrm{C}$ which is close to the PET $T_{g}$. Due to the very low crystalline content of the PET as received samples there is relatively little preexisting crystalline material to be destroyed during deformation and the crystallinity of all tested samples increases during deformation. The increase in flow stress for samples tested at the same temperature is directly related to the crystallinity level of the sample.

Table 1: Summary of PET results: crystallinity (\%) and flow stress at strain $=0.1$

$\begin{array}{cccc}\text { Temp }{ }^{\circ} \mathrm{C} & \text { Untested } & 10^{-3} \mathrm{~s}^{-1} & 10^{2} \mathrm{~s}^{-1} \\ 20 & 9 \% & 16 \% \text { and } 70 \mathrm{MPa} & 48 \% \text { and } 122 \mathrm{MPa} \\ 50 & 11 \% & 14 \% \text { and } 33 \mathrm{MPa} & 41 \% \text { and } 154 \mathrm{MPa} \\ 90 & 18 \% & 37 \% \text { and } 14 \mathrm{MPa} & 43 \% \text { and } 67 \mathrm{MPa}\end{array}$




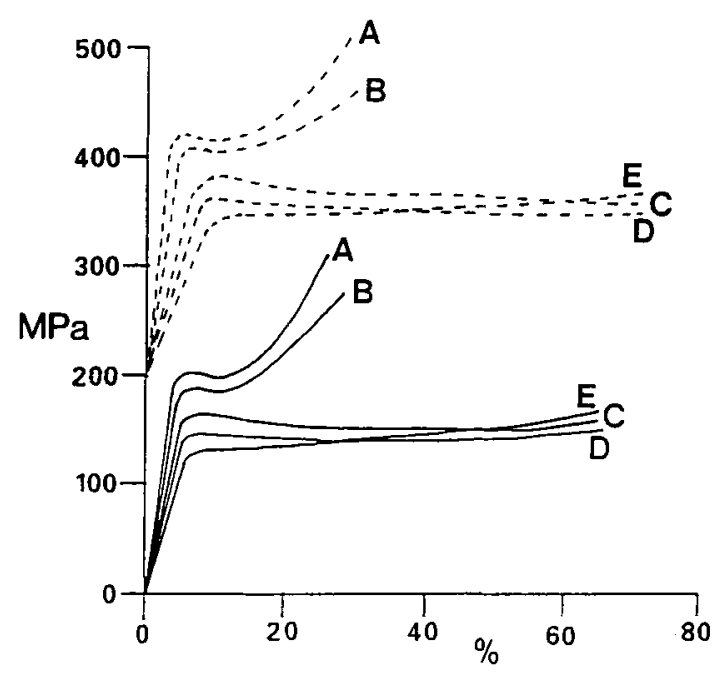

Figure 1: Stress strain data for PEEK (- $\left(-\right.$ and PEK (- - - ) tested at $20^{\circ} \mathrm{C}$. PEK data is offset by $200 \mathrm{MPa}$. Strain rates (A) 2000/s, (B) $1000 / \mathrm{s}$, (C) $500 / \mathrm{s}$, (D) $10 / \mathrm{s}$ (E) 0.001/s.

\subsection{Thermal analysis}

Thermal analysis was performed on $\sim 5 \mathrm{mg}$ samples cut from the untested and tested samples. The equipment used was a Mettler TA3000 system. The heating rates used were either 10 or $20^{\circ} \mathrm{C} / \mathrm{min}$. The heat of fusion obtained is directly proportional to the crystallinity. The degree of crystallinity $(\chi)$ was calculated from:

$$
\chi=\mathrm{H} / \mathrm{H} \mathrm{f}
$$

where $\mathrm{H}$ is the heat of fusion per gram obtained from the non-isothermal DSC scan and Hf is the heat of fusion of $100 \%$ crystalline PEEK $130 \mathrm{~J} / \mathrm{g}$ [7] or $100 \%$ crystalline PET $115 \mathrm{~J} / \mathrm{g}$ [15]

Table 2 summarises the crystallinity of samples of PEK and PEEK after testing at a range of temperatures and strain rates. The crystallinity tabulated is calculated by subtracting the DSC induced cold crystallisation peaks from the melting endotherm before converting to crystallinity and hence represents the crystallinity of the sample at the end of the test. Modest amounts of cold crystallisation were observed in PEK and PEEK in all samples except those tested at a strain rate of $10^{3} \mathrm{~s}^{-1}$ at temperatures above $\mathrm{Tg}$ and, not surprisingly, the annealed but untested samples. This is contrary to the results of previous workers who observed a far greater amount of cold crystallisation in all samples tested below $\mathrm{Tg}$ and an absence of cold crystallisation in samples tested at and above Tg. For tested samples up to $100 \mathrm{~s}^{-1}$, the crystalline content has been reduced during mechanical deformation as shown by the crystallinity level $(\%)$. Samples tested at $1000 \mathrm{~s}^{-1}$ however have a greater crystalline content. The observed increase in crystallinity in all samples tested at $10^{3} \mathrm{~s}^{-1}$ is also anomalous since all previous work on PEEK and all other PEEK results presented here show a decrease in crystallinity after strain. However other workers have not carried out tests at such high rates. The increase in $1000 \mathrm{~s}^{-1}$ melting endotherm might reflect either the increase in perfection of the crystalites or an increase in crystalline content. X-ray diffraction, presented below, was used to attempr to distinguish between these possibilities.

The results of the DSC measurements on PEK and PEEK can be summarised as follows. In all of the tests at strain rates from $10^{-3} \mathrm{~s}^{-1}-100 \mathrm{~s}^{-1}$ the crystallinity level in the tested samples is lower than the annealed samples. This is probably due to destruction of the crystal structure and/or void formation as described by previous workers. For samples tested at very high rates i.e. $1000 \mathrm{~s}^{-1}$. SIC due to the crystallisation of aligned chains gives a higher degree of crystallinity and the crystallinity level peaks for tests carried out at about $T_{g}$. In the case of PET crystallinity greatly increases with increased strain rate with the highest recorded value of flow stress being for tests conducted close to $T_{\mathrm{g}}$. There was however no obvious link between the crystalline content and test temperature at the higher rate tests although a trend of increase in crystallinity with test temperature in low rate tests and untested material is evident. This suggests that SIC in PET cannot exceed values in the range 40-50\%. Such a conclusion is supported by the results of other workers (Spruiell [5], Evstatiev et al [16] ) none of whom record SIC greater than $46 \%$ before annealing. The data for PET is not yet nearly as comprehensive as that for the other materials but the general trends in behaviour seem similar to those for PEK and PEEK. 
Tabole 2: Crystallinity levels $(\%)$ \& flow stress ( $\mathrm{MPa}$ at strain $=0.3$ ) for PEEK and PEK at a range of strain rates and test temperatures $\left({ }^{\circ} \mathrm{C}\right)$.

\begin{tabular}{ccccccccccc}
\multicolumn{1}{c}{ PEEK } & \multicolumn{3}{c}{ PEK } \\
Temp ${ }^{\circ} \mathrm{C}$ & Untest & $10^{-3} / \mathrm{s}$ & $\begin{array}{c}\text { Strain } \\
10 / \mathrm{s}\end{array}$ & $\begin{array}{c}\text { Rate } \\
10^{2} / \mathrm{s}\end{array}$ & $10^{3} / \mathrm{s}$ & Untest & $10^{-3} / \mathrm{s}$ & $\begin{array}{c}\text { Strain } \\
10 / \mathrm{s}\end{array}$ & $\begin{array}{c}\text { Rate } \\
10^{2} / \mathrm{s}\end{array}$ & $10^{3} / \mathrm{s}$ \\
$20^{\circ}$ & 38 & $23 \& 141$ & $30 \& 145$ & $30 \& 148$ & $35 \& 370$ & 44 & $36 \& 166$ & $35 \& 160$ & $33 \& 160$ & $39 \& 280$ \\
$60^{\circ}$ & 33 & $29 \& 131$ & $27 \& 135$ & $30 \& 133$ & $38 \& 340$ & 40 & $35 \& 138$ & $33 \& 149$ & $33 \& 145$ & $44 \& 275$ \\
$80^{\circ}$ & 34 & $30 \& 125$ & $27 \& 125$ & $30 \& 126$ & $39 \& 268$ & 43 & $31 \& 137$ & $34 \& 146$ & $29 \& 143$ & $46 \& 265$ \\
$100^{\circ}$ & 40 & $29 \& 116$ & $30 \& 119$ & $30 \& 122$ & $45 \& 230$ & 41 & $33 \& 125$ & $32 \& 134$ & $33 \& 134$ & $48 \& 230$ \\
$120^{\circ}$ & 39 & $26 \& 117$ & $29 \& 100$ & $32 \& 110$ & $46 \& 182$ & 44 & $34 \& 131$ & $34 \& 109$ & $34 \& 128$ & $50 \& 264$ \\
$140^{\circ}$ & 36 & $30 \& 112$ & $28 \& 96$ & $28 \& 108$ & $47 \& 210$ & 44 & $31 \& 123$ & $34 \& 113$ & $32 \& 118$ & $53 \& 228$ \\
$160^{\circ}$ & 38 & $26 \& 111$ & $29 \& 102$ & $29 \& 102$ & $44 \& 168$ & 39 & $32 \& 125$ & $34 \& 115$ & $34 \& 116$ & $52 \& 255$ \\
$180^{\circ}$ & 38 & $27 \& 105$ & $28 \& 106$ & $30 \& 98$ & 46 & 44 & $34 \& 122$ & $30 \& 123$ & $37 \& 112$ & $51 \& 222$
\end{tabular}

\subsection{X-ray Work}

Wide angle $\mathrm{x}$-ray diffraction (WAXD) patterns in reflection mode using $\mathrm{CuK} \alpha$ radiation were recorded using a 'Unicam' camera and also a Philips PW1050/25 diffractometer. The combined WAXD of the annealed and high strain rate $\left(1000 \mathrm{~s}^{-1}\right)$ PEEK samples are shown in figure 2 for $2 \theta$ ranging from $10^{\circ}-35^{\circ}$. These patterns were measured on samples in which the end plane of the cylindrical sample (the plane of compression) was oriented perpendicular to the $\mathrm{x}$-ray beam. The temperatures refer to the test temperature. The main (hkl) reflections are (110) at around $18.5^{\circ}$, (113) near $20.5^{\circ},(200)$ near $22.5^{\circ}$ and (213) near $28.5^{\circ}$ while the positions of these four major peaks observed by Fratini et.al [17] during crystal refinement work on PEEK, also using copper radiation, are at $18.76^{\circ}, 20.82^{\circ}, 22.72^{\circ}$ and $28.78^{\circ}$ respectively. In general the crystal reflection from the tested samples are very broad and poorly resolved, indicative of an imperfect crystal structure. Figure 3 shows a similar (though less comprehensive) set of data for PET.

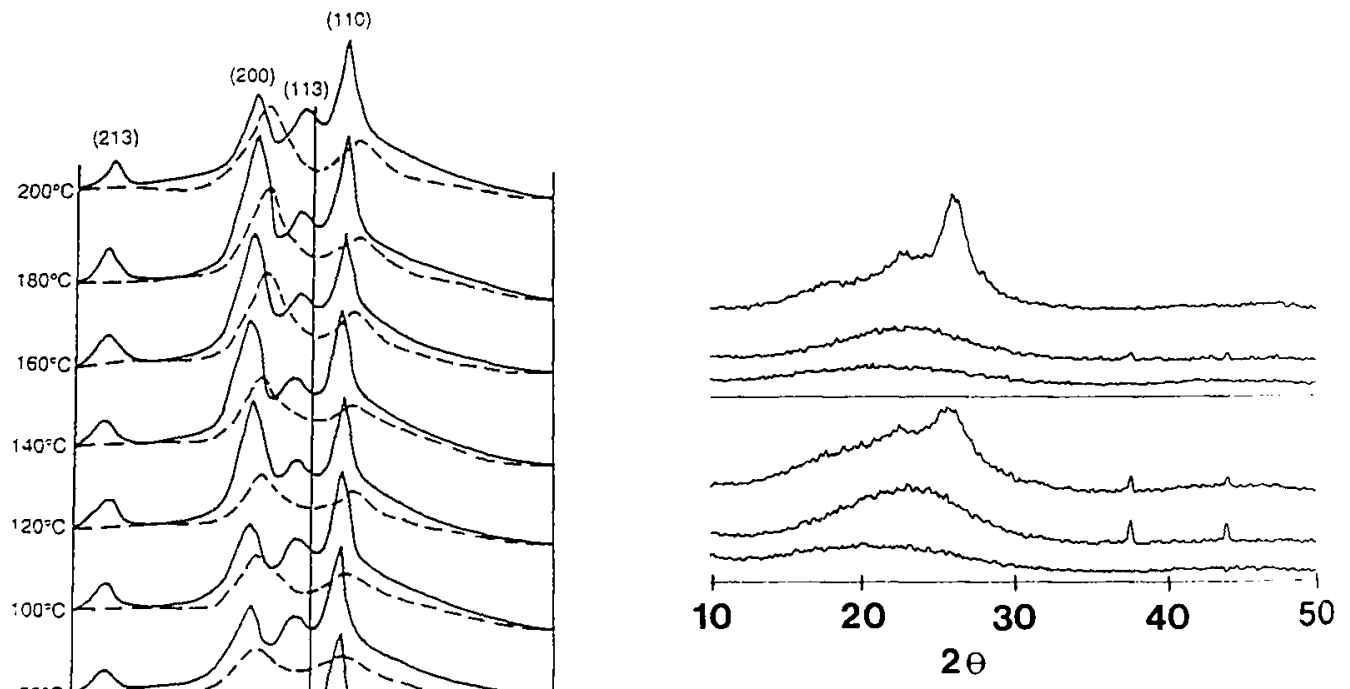

Figure 3: Diffraction patterns of PET samples.

Upper group Room Temperature tests, Lower group $50^{\circ} \mathrm{C}$ tests. In each group the lower trace is of an untested sample, middle trace is of a sample tested at a strain rate of $.001 / \mathrm{s}$ and the upper trace is from a sample tested at $100 / \mathrm{s}$.

Figure 2: Diffraction patterns of untested (___ ) and tested (- - - - ) PEEK samples. Temperatures indicate the test temperature. All patterns were obtained at room temperature. 
For the PEEK/PEK samples there is a marked progressive change in the peak intensity and decrease in width with increasing temperature for the samples tested at $1000 \mathrm{~s}^{-1}$ but this pattern is not observed for the samples tested at the other strain rates which only show a slight improvement in the peaks for samples tested at higher temperatures. Figure 2 shows that there are small changes in the reflection angles and also the disappearance of the (113) and (213) peaks in the samples tested at $10^{3} \mathrm{~s}^{-1}$. These changes in the reflection angles indicate changes in the lattice dimension and the 'loss' of the (113) and (213) peaks indicates that orientation occurs during compression. The pattern of annealed and untested samples is virtually identical to a broadened version of the unoriented diffraction pattern reported by Fratini et.al [17]. X-rays taken in a direction perpendicular to those described above showed a similar but not as dramatic change in $\mathrm{d}$ spacing.

In the PEEK/PEK samples the only peak whose position that could be determined with accuracy was the (200). The corresponding lattice spacing as a function of testing temperature and rate is set out in Table 3 . The refined (200) PEEK spacing reported by Fratini et al. is $3.93 \AA$. Almost all the measured lattice spacings exceed this value but are close to the measured values reported by Fratini et al of $3.96 \AA$. The only exceptions are the $10^{3} \mathrm{~s}^{-1}$ samples where the ' $\mathrm{d}$ ' spacings fall below both the reported measured and refined values. After this observation the system calibration was checked with a silicon standard and all the $d$ spacings were observed to lie $<0.01 \AA$ from their expected values. This result indicates an increase in crystalline perfection as well as content occurs at high rates in these samples. In the case of the PET samples there was no change in the lattice spacings from the expected values after any of the tests. This would seem to indicate that crystalline content is the main factor leading to increased flow stress in high strain rate tests.

\section{DISCUSSION}

The results of this work show that the previously reported behaviour of PEEK $[9,10,11]$ is representative of the behaviour of both PEEK and the closely related polymer PEK at strain rates up to $10^{2} \mathrm{~s}^{-1}$ and test temperatures up to $200^{\circ} \mathrm{C}$. The observation of a large increase in crystallinity in samples tested at the highest strain rates coupled with an increase in crystalline perfection in those samples tested at high rates and high temperature provides an explanation for the increase in yield strength of samples of PEEK and PEK tested above Tg reported elsewhere [18]. There have in the past been many reports of dramatic increases in yield stress of polymers at strain rates of $10^{2}-10^{3} \mathrm{~s}^{-1}[3,4]$ and there is much discussion as to whether or not these are genuine material effects or merely apparent increases in yield stress caused by instrumental effects. The results presented here suggests that such increases, at least in semi-crystalline polymers are indeed genuine and are caused by a combination of increased crystallinity and crystalline perfection which appears to be induced by the high strain rate. The reason for this dramatic change at these strain rates is not clear. The possibility that it is related to the total strain has been considered, however no relationship between lattice spacing and strain has emerged and the work of Spruiell et al. showed very little strain effects on crystallinity at strains greater than 1. The adiabatic nature of tests performed at high rates means that rapid heating of the sample occurs during the test [19] so that high rate tests performed on PET close to room temperature may increase sample temperatures sufficiently close to $\mathrm{Tg}$ for transformation to a morphology with a much increased flow stress to occur. Calculations of the adiabatic temperature rises expected at a strain of 0.2 lead to the conclusion that the $50^{\circ} \mathrm{C}$ PET sample will have risen in temperature by $\sim 17^{\circ}$ bringing it very close to $T_{g}$. Temperature rises in PEEK/PEK are a little higher so that all tests conducted on these materials at $120^{\circ}$ or above would lead to samples reaching $\mathrm{T}_{\mathrm{g}}$. Although the rate of SIC should increase with temperature upto the cold crystallisation temperature the flow stress of the material should decrease rapidly above $\mathrm{T}_{\mathrm{g}}$ due to the viscoelastic behaviour of the material We therefore speculate that the rate of strain hardening due to SIC should be greatest in the region of $T_{g}$ and that this accounts for the increase in flow stress observed in all three materials in tests at high rates around $\mathrm{T}_{\mathrm{g}}$.

\section{Acknowledgements}

The authors are grateful to the U.K. Engineering and Physical Sciences Research Council (EPSRC) for the provision of financial support under grant GR/L14220.

\section{References}

[1] Gorham D.A., Pope P.H. and Cox O., Proc. 3dh conf. on mech. Prop at high rates of strain. I.O.P conf. series No. 70 (1984) 151-158.

[2] Klepaczko J.R., J. de Physique C3 49 (1988) 553-560.

[3] Chou S.C., Robertson KD. and Rainey J.H., Experimental Mechanics, 13 (1973) 422-432.

[4] Briscoe B.J., and Nosker R.W., Polymer Communications, 26 (1985) 307-308.

[5] Spruiell J.E., McCord D.E., Beuerlein R.A., Trans. Soc. Rheol 16 (1972) 535-555 
[6] Attwood T.E., Dawson P.C., Freeman J.L., Hoy L.R.J., Rose J.B. and Staniland P.A., Polymer, 22 (1981) 1096-1103.

[7] Blundell D.J. and Osborn B.N., Polymer, 24, (1983) 953-958.

[8] Daubeny R., Bunn C.W. and Brown C.J. Proc. Roy. Soc. Lond. A226 (1954) 531-542

[9] Cebe P., Chung S.Y. and Hong S-D., Journal of Applied Polymer Science, 33 (1987) 487-503.

[10] Lee L.H., Vanselow J.J. and Schneider N.S., Polymer Engineering and Science, 33 (1988) 181-187 .

[11] Russo R., Journal of Applied Polymer Science, 46 (1992) 2177-2181.

[12] Jabarin S.A. Polymer Engineering and Science, 32 (1992) 1341-1349.

[13] Hamdan S. and Swallowe G.M., Meas. Sci and Technol.,7 (1996) 1068-1072

[14] Zeng X., Hamdan S., and Swallowe G. M., Proc. 2dh Intl. Symp. on Impact Engineering, Beijing 1996 Chinese Journal of Mechanics (1996) 374-379.

[15] Mettler TA3000 system manual, Mettler Instruments AG 1984 p.77

[16] Evstatiev M., Fakirov S., Apostolov A., Hristov H. and Schultz J.M., Polymer Eng. and Sci. 32 (1992) 964-970.

[17] Fratini A.V., Cross E.M., Whitaker R.B. and Adams W.W., Polymer, 27 (1986) 861-865.

[18] Hamdan S. and Swallowe G.M., J. Mat. Sci, 31 (1996) 1415-1423.

[19] Frost H. J., and Ashby M. F., Deformation Mechanism Maps, Pergamon Press, Oxford, 1982, p120. 